\title{
Subjetividad y conocimiento
}

\author{
Diana Helena Maffía
}

U

n tema recurrente en la epistemología feminista es la crítica a las dicotomías que dominan la producción de conocimiento científico, en la que una de las categorías del par tiene valor epistémico reconocido, y a la otra se le niega. Pares conceptuales como universal/particular, abstracto/concreto, hechos/valores, razón/emoción y otros, han sido analizados como dispositivos del sexismo implícito en las teorías científicas y filosóficas, que deben ser desarticulados y comprendidos en su alcance. La dicotomía masculino/femenino superpuesta a esos pares conceptuales nos ubica siempre del lado cognitivamente desvalorizado, del lado de aquellas experiencias demasiado triviales y particulares como para otorgarles valor epistémico, justificando asi el desajuste de las mujeres con el ideal de una vida abstracta de pura razón, propio de la ciencia.

Las feministas han tenido buenos motivos para criticar este presupuesto de la falta de autoridad cognitiva, porque al fundarse en un aspecto metafisico como es la naturaleza humana puede parecer un problema abstracto, pero tiene consecuencias muy concretas. Como señala la epistemóloga Lorraine Code, las dicotomías son especialmente problemáticas puesto que afirman constructos exhaustivos y excluyentes, no complementarios o interdependientes que pudieran funcionar como modos "mixtos". La continuidad entre los términos es una imposibilidad lógica, funciona como los contradictorios aristotélicos que afectan el universo entero del discurso. Desde tal dicotomía, el lado derecho se asocia con el desorden, la irracionalidad, la impureza, el error; y aplicado al mundo funciona para mantener el orden, se vuelve un instrumento de opresión social.

Una de las dicotomías más importantes para la filosofia de la ciencia es objetivo/subjetivo. Y de la remisión de las mujeres a una esfera de pura subjetividad ha derivado no sólo la falta de autoridad cognitiva, sino importantes consecuencias sociales, jurídicas y políticas asociadas a ella. Con muy 
pocas excepciones, la historia de la filosofia occidental se ha ocupado de afirmar (cuando no ha contado implícitamente con ello) que nuestra emotividad, nuestra inclinación a la esfera de lo particular y a la subjetividad, no nos hacen aptas para lo que se consideran las más altas expresiones de lo humano: la moral, la ciencia, la política y la filosofia.

Al sujeto cognitivo se le impone de modo simplista una opción entre ajustarse el corsé de hierro de la objetividad, o sucumbir a los caprichos de la subjetividad desenfrenada. No hay término medio: la subjetividad recoge todo lo caótico e inestable que no exhibe ninguno de los rasgos de la objetividad, y por eso no tiene valor epistémico. De hecho, la objetividad y la neutralidad a ella asociada, son criterios que según la tradición distinguen el genuino conocimiento de la mera creencia, opinión o fantasía. Para el pensamiento epistemológico tradicional, incluir la subjetividad significa dar un paso al abismo de la arbitrariedad, donde ningún punto de vista podría prevalecer sobre el otro de modo legítimo, o en el peor de los casos incluso no podrian comunicarse entre sí.

Para escarmiento están los filósofos que han reclamado un camino subjetivista para el conocimiento, corriendo el riesgo del relativismo extremo y del solipsismo. Uno de estos filósofos, Edmund Husserl, fundador de la fenomenología, sostenía un argumento que hoy suscribirian muchas feministas: la ciencia moderna, encarnada en Galileo, produjo un gran olvido. Si Galileo fue un gran descubridor, no es menos cierto que fue también un gran encubridor. Lo que encubre es la labor constitutiva del sujeto, los intereses humanos que dan origen a la ciencia; y al hacerlo genera la ilusión de un puro orden mecánico que gobierna la naturaleza, un orden objetivo independien. te de todo sujeto. Los objetos, aquellos que parecen constituir nuestra experiencia más simple, son en realidad una abstracción. Nunca nos enfrentamos con un mundo circundante de meras cosas, dice Husserl. Lo que nos es dado son siempre cosas cargadas de significados valorativos y prácticos. El mundo de la ciencia tiene un suelo sin el cual no puede constituirse y al cual después silencia: el mundo de la vida.

Husserl toca aquí un problema asociado a la objetividad, y es el de la neutralidad (otro desideratum de la teoría tradicional del conocimiento, conectado a la dicotomía hechos/valores). A veces, objetividad y neutralidad valorativa son virtualmente sinónimos. Es casi una herejía sugerir que ciertos intereses específicos motivan y conforman la investigación. Para la concepción heredada, los productos del capricho no pueden ser llamados conocimiento, porque no hay criterio para elegir entre ellos. Por contraste, el conocimiento objetivo es neutral con respecto a los valores y se presenta como una colección de hechos o verdades imparciales y desinteresadas. Es justamente esta colección la que para Husserl es imposible. Sin interés humano, 
sin objetos valorizados y significados por el sujeto, no hay mundo, y por ende no hay ciencia.

Cuando se habla de disolver una dicotomía no se quita significado a sus términos, sino que se niega la fuerza absoluta que la estructura oposicional de la dicotomía les confiere. Es válido preguntarse si para incorporar elementos subjetivos es preciso renunciar a la objetividad. Porque si bien desde mi punto de vista es un error menospreciar la subjetividad, no lo seria menos negar valor epistémico a la objetividad. Que la ciencia sea androcéntrica no significa que las feministas debamos deshacernos de ella. El reto es mostrar que la objetividad requiere tomar en cuenta la subjetividad. La propuesta está inmersa en la búsqueda de una teoría del conocimiento viable que recoja la diversidad de experiencias cognitivas, y donde las dicotomías y su jerarquía epistémica obstaculizan el logro. Se propone reemplazar los términos opuestos tradicionales por una lectura que revele el lugar en una trama en que están situadas las experiencias de los agentes cognitivos.

El valor concedido a la neutralidad valorativa se debe al lugar acordado al conocimiento científico (que alega ser neutralmente valorativo) entre los logros intelectuales humanos. Los epistemólogos comúnmente evalúan el conocimiento de acuerdo a su éxito en la aproximación a los criterios metodológicos y epistemológicos de las ciencias físicas. Y está implícita en la veneración de la objetividad, central a la práctica científica, la convicción de que los objetos de conocimiento están separados de los conocedores e investigadores, y que permanecen separados y sin cambios a través de los procesos de investigación, acopio de información y construcción del conocimiento.

De acuerdo con la ortodoxia científica, las leyes generales y universales pueden formularse sobre la base de observaciones empíricas, y tales leyes capacitan al investigador para predecir (de una manera totalmente desinteresada) cómo pueden ser afectados los objetos en ciertas circunstancias controladas. La concepción estrictamente objetivista de la ciencia presenta a la física como la más pura de las ciencias, con una metodología inmune a la influencia social. El método científico al que se da estatuto de paradigma, entonces, es el de una especie altamente especializada (y en cierto modo atípica) de práctica científica. El hecho de que la objetividad perfecta no es fácil de lograr en otras áreas, excepto deformando el objeto de estudio, pone en duda la alegada supremacía e inmunidad de la física. En lugar de preguntar por qué otras disciplinas (como la biología, la antropología o la psicología) son deficientes con respecto a la física, podríamos preguntar por qué la fisica se ha constituido en paradigma de objetividad.

La concepción de objetividad derivada de la física depende de una construcción particular de la relación entre sujeto y objeto de conocimiento. Lo que produce el conocimiento no es aqui la subjetividad del científico sino la 
objetividad del método científico. La subjetividad es vista con sospecha, como un posible agente de contaminación del proceso de producción del conocimiento, que debe gobernarse con controles estrictos. La identidad del sujeto de la ciencia, como el del conocimiento, es irrelevante para la práctica de investigación. Por cierto no posee sexo, pero tampoco genio, inspiración, excentricidad, preferencias, cegueras, privilegios de clase, raza o etnicidad. La perfecta neutralidad marca su observación distanciada del objeto en condiciones perfectamente controladas para maximizar la objetividad.

Cuando esta metodología se traslada al contexto de las ciencias sociales, en la que el objeto de estudio son los seres humanos, ocurre una doble supresión de la subjetividad. Las teorías y métodos de investigación en ciencias sociales objetivan los sujetos humanos que estudian. No se toman en cuenta ni la conciencia de los sujetos estudiados ni el significado y la interpretación de sus experiencias por tales sujetos. La conducta humana se transforma en otro dato observacional. Y puesto que se trata de un dato sumamente elusivo, la inferioridad de las ciencias sociales parece dictada por decreto. Desaparece la subjetividad del investigador y del investigado, pretendiendo que esto enriquece el conocimiento y lo torna más adecuado a las exigencias de la ciencia.

El psicoanálisis feminista, con su revisión de la conformación de la identidad personal y sexual de los sujetos, ha aportado a la epistemología elementos críticos muy valiosos para sugerir que esta separación entre el sujeto y el objeto corresponde en realidad a un tipo determinado de subjetividad: la masculina. Los cientificos han transformado en método neutral un modo de abordaje del mundo que no desestructure su identidad sexual. El estudio del vínculo que las científicas establecen en la relación de conocimiento (sobre todo en la espléndida biografia que la epistemóloga Evelyn Fox Keller hizo de la premio nobel Barbara McClintock) sugiere que otros modos más comprometidos de conocimiento, que involucran la subjetividad, resultan finalmente exitosos aún para los parámetros usuales. El precio, si la ciencia va a permanecer tal cual está, es la marginalidad. Y la cuestión del centro y el margen es un problema para el feminismo académico en general, y no sólo el científico, que merece una discusión detallada.

Volviendo a la fenomenología, señala Husserl que no hay acceso posible al mundo objetivo si no es a través del conocimiento de los otros sujetos. La perspectiva del mundo de cada sujeto es el producto de una interpretación de los datos que le son ofrecidos, interpretación que excede los límites de la propia percepción. No habría modo de salir del mero contenido individual de la conciencia si no es estableciendo una analogía entre la propia capacidad constitutiva y de relación con el propio cuerpo, y los otros sujetos a los que les atribuyo capacidades semejantes. De esta situación original, un suje- 
to que ante otro lo considera alguien a cuya conciencia no puede acceder pero a quien atribuye condiciones idénticas a las propias, surge una particular visión del mundo y de sí mismo.

Puede dar la impresión de que el conocimiento del otro es filosóficamente inmanejable. La pretensión de que los sujetos son cognoscibles choca con la afirmación psicoanalítica del inconsciente, y más aún con la crítica posmoderna a las teorías que presuponen un yo unificado. Esto (como agudamente señala la epistemóloga Lorraine Code) produce una tensión. Conocer otra gente, precisamente por las fluctuaciones y contradicciones de la subjetividad, es un proceso activo, comunicativo e interpretativo. Nunca puede ser fijo y completo: cualquier fijeza que se le atribuya al yo es a lo sumo una fijeza en un fluir. Pero también presupone una fijeza, pues algo debe detener el flujo lo suficiente como para permitir la referencia y la relación con esa persona. La suposición de que uno conoce a otra persona debe hacerse en los términos de esta tensión.

Generalizar un abordaje interpretativo de este tipo a otras clases de conocimiento nos previene contra el dogmatismo: el conocimiento del otro sólo es posible en un interjuego entre opacidad y transparencia, entre actitudes y posturas que eluden la comprensión del conocedor y rasgos que parecen claros y relativamente constantes. Esto afirma la necesidad de revisar los juicios y hacerlos con reservas. $Y$ traspuesta a lo político, esta actitud es una invitación a la tolerancia. Para esto resulta útil el concepto de "horizonte" desarrollado por Husserl, sobre todo en su concepción del mundo como horizonte, es decir como un trasfondo necesario y permanente, que nunca se percibe totalmente, y que ninguna conciencia humana individual podría contener. La validez de toda cosa y del mundo mismo, es una pretensión de validez intersubjetiva.

El modelo que acabamos de describir, donde el objeto es tan mudable como el sujeto y se interfieren mutuamente, contrasta con el paradigma objetivista tradicional que se maneja con objetos que manifiestan un alto grado de permanencia. Al conocer a otro, la subjetividad del conocedor y del conocido se comprometen: en el conocimiento la subjetividad de ambos se desarrolla y cambia. Además la posición de conocedor y conocido no permanece fija, es siempre intercambiable en principio. Por lo tanto, este conocimiento trabaja con una concepción de la relación sujeto-objeto diferente de aquella a la que implícitamente apela el paradigma de los conocimientos empíricos simples. La pretensión de conocer a otra persona está abierta a cierta "negociación" entre el conocedor y el conocido, donde las posiciones de objeto y sujeto son siempre intercambiables en principio.

El modelo contrasta así también con la concepción subjetivista que propone un privilegio cognitivo sobre los propios contenidos de conciencia. 
Según este proceso, podría haber discrepancias entre la concepción que un sujeto tiene de sí mismo y la que otros tienen de él. La propia subjetividad está sujeta a la concepción que quien ha de ser conocido tiene de ella, pues ni la autoconcepción ni la concepción del otro pueden pretender una autoridad absoluta y última, por los límites de la autoconciencia que constriñen la observación del proceso de interioridad de lo mental.

El proceso de conocer a otros requiere un constante aprendizaje. Si consideráramos también así el conocimiento del mundo físico, deberíamos re. conocer que hacer un informe observacional es una habilidad adquirida en un lento y tentativo proceso de juicio. Precisamente este reconocimiento marca la diferencia en la fenomenología de Husserl entre un primer periodo "estático" y uno posterior "genético". Pero del compromiso de la subjetividad en el conocimiento no debe extraerse la conclusión de que el conocimiento es subjetivo. Hay hechos objetivos que constituyen lo que una persona es, y que deben tenerse en cuenta para conocerla. Ciertas cosas pueden afirmarse sobre otro sujeto y otras simplemente no. Hay datos objetivos en el sentido ordinario: lugar y fecha de nacimiento, sexo, altura, color de pelo, etcétera. También hay informes objetivos como su matrimonio o divorcio, maternidad, empleo, educación, habilidades, etcétera. Lo verdaderamente extraño es que aun conociendo todos los hechos sobre alguien, no podríamos conocerlo como la persona que es. Así como conocer todos los hechos de la propia vida no garantiza el autoconocimiento. Pero no es razonable que eso nos haga dudar de nuestra existencia o de la existencia del otro.

No hay buenas razones para creer que tomar en cuenta la subjetividad implique un abandono de la objetividad. En cambio, afirmar que el conocimiento es tanto subjetivo como objetivo, tomando el conocimiento del otro como eje, nos abre la posibilidad, sin abandonar la ciencia como paradigma de conocimiento, de considerar la física como un caso muy enrarecido y encontrar más natural la apelación a una ciencia social reconstruida. El eje de análisis vira completamente, poniendo a las ciencias sociales como las más cercanas a los modos naturales de conocimiento, y las ciencias físicas como una abstracción que no puede realizarse sino sobre ese suelo original de contacto con los otros.

Varios aspectos de la subjetividad juegan un papel constitutivo en la construcción del conocimiento: la ubicación histórica, la identidad racial, étnica, de clase, edad, género; el contexto social y lingüistico, la creatividad, el compromiso, los intereses. Estos constituyentes son subjetivos en el sentido de que derivan de las circunstancias y prácticas del sujeto cognoscente. Tradicionalmente se les ha separado de la razón y el intelecto. Ello ha empobrecido, a mi juicio, el conocimiento; tanto como la exclusión de lo femenino ha empobrecido por milenios la concepción de lo humano. 